\title{
Influence of fructooligosaccharides on the fermentation profile and viable counts in a symbiotic low fat milk
}

\author{
Ricardo P.S. Oliveira ${ }^{1,2}$, Alessandro A. Casazza ${ }^{2}$, Bahar Aliakbarian $^{2}$, Patrizia Perego ${ }^{2}$, \\ Attilio Converti ${ }^{2}$, Maricê N. Oliveira ${ }^{1}$ \\ ${ }^{1}$ Departamento de Tecnologia Bioquímico-Farmacêutica, Universidade de São Paulo, \\ São Paulo, SP, Brazil. \\ ${ }^{2}$ Department of Chemical and Process Engineering, University of Genova, Genova, Italy.
}

Submitted: September 20, 2011; Approved: June 5, 2012.

\begin{abstract}
This study evaluated the effects of prebiotics on fermentation profile and growth of Lactobacillus acidophilus, Lactobacillus bulgaricus, Lactobacillus rhamnosus, and Bifidobacterium lactis in co-cultures with Streptococcus thermophilus. Acidification rate and viability were positively influenced by the co-culture with $B$. lactis and by both inulin or oligofructose in low fat milk.
\end{abstract}

Key words: Lactobacillus, Bifidobacterium, Fructooligosaccharide, fermented milk.

In recent years, consumers are increasingly demanding foods with pleasant flavor, low-calorie value or low fat content, and beneficial health effects (Vasiljevic and Shah, 2008; Paseephol and Sherkat, 2009). Within this context, the food industry has been trying to offer products with improved flavor and appearance. In addition, functional dairy products offer requirements and benefits to the health that are strengthened by the addition of probiotics, as well as of certain types of soluble fibers, such as oligofructose, inulin and lactulose, known as prebiotics.

Inulin and oligofructose are common forms of prebiotics (Gibson and Roberfroid, 1995; Angus et al., 2005). According to Gibson and Roberfroid (1995), prebiotic is a non-digestible food ingredient that beneficially affects the host by selectively stimulating the growth and/or activity of one or a limited number of bacteria in the colon, that have the potential to improve host health. Regarding technological applications, inulin is mostly applied to obtain products with low fat content, while oligofructoses are employed in low-calorie fruit preparations such as yoghurts, as well as to balance the sweetness and mask the high-intensity sweetener's residual flavor used in food preparations (Niness, 1999). In addition, Oliveira et al. (2011) reported that inulin has the additional advantage of improving the firmness of functional dairy fermented products.
On the basis of this background, oligofructose and inulin appear as important food ingredients that should be additionally explored for the production of new functional dairy products. Therefore, the aim of the present study was to evaluate the effects of these prebiotics on the fermentation profiles and viable counts of co-cultures of Lactobacillus acidophilus, L. bulgaricus, L. rhamnosus, and Bifidobacterium lactis with Streptococcus thermophilus.

Streptococcus thermophilus TA040 (St), Lactobacillus delbrueckii subsp. bulgaricus LB340, Lactobacillus acidophilus LAC4 (La), Lactobacillus rhamnosus LBA (Lr), and Bifidobacterium animalis subsp. lactis BL 04 were used as commercial starter cultures (Danisco, Sassenage, France) in this study. All strains were inoculated in sufficient amounts to get initial counts of $10^{6} \mathrm{cfu} / \mathrm{mL}$. Figure 1 represents a schematic flow chart of milk preparation and fermentation process. The skim milk (Castroni, Reggio Emilia, Italy) was supplemented with the prebiotics oligofructose (Orafti $\left.{ }^{\circledR} \mathrm{P} 95\right)$ and inulin (Ora$\left.\mathrm{fti}^{\circledR} \mathrm{GR}\right)$ (Orafti Active Food Ingredients, Oreye, Belgium). The maximum acidification rate $\left(\mathrm{V}_{\max }\right)$ was calculated as the time variation of $\mathrm{pH}(\mathrm{dpH} / \mathrm{dt})$ and expressed as $10^{-3} \mathrm{pH}$ units/min. The time to reach $\mathrm{pH} 4.5\left(\mathrm{~T}_{\mathrm{f}}\right)$ was assumed as the time to complete the fermentation. Viable cell counts were made in triplicates after fermentation, as previously de-

Send correspondence to R.P.S. Oliveira. Department of Biochemical and Pharmaceutical Technology, University of São Paulo, Av. Prof Lineu Prestes 580, B1 16, 05508-900 São Paulo, SP, Brazil. E-mail: rpsolive@usp.br. 


\begin{tabular}{|c|c|c|}
\hline Skin milk (Control) & Skim milk + Inulin & Skim milk + Oligofructose \\
\hline \multicolumn{3}{|c|}{$\downarrow$} \\
\hline \multicolumn{3}{|c|}{ Heat treatment $\left(90^{\circ} \mathrm{C} / 5 \mathrm{~min}\right)$} \\
\hline \multicolumn{3}{|c|}{$\downarrow$} \\
\hline \multicolumn{3}{|c|}{ Coolin $\left(4^{\circ} \mathrm{C}\right)$} \\
\hline \multicolumn{3}{|c|}{1} \\
\hline \multicolumn{3}{|c|}{ Inoculation of Co-cultures } \\
\hline \multicolumn{3}{|c|}{$\downarrow$} \\
\hline & \multicolumn{2}{|c|}{ Fermentation $\left(42^{\circ} \mathrm{C}\right.$ up to $\left.\mathrm{pH} 4.5\right)$} \\
\hline
\end{tabular}

Figure 1 - Schematic flow chart of milk preparation and fermentation process.

scribed by Oliveira et al. (2009a). Samples $(1.0 \mathrm{~mL})$ were added to $9.0 \mathrm{~mL}$ of $0.1 \%$ sterile peptone water; then, appropriate dilutions were made, and each bacterium was counted in the three most appropriate dilutions, applying the pour plate technique. Subsequently, S. thermophilus was plated into M17 agar (Oxoid, Basingstoke, UK) and then submitted to aerobic incubation at $37{ }^{\circ} \mathrm{C}$ for $48 \mathrm{~h}$. Enumeration of $L$. bulgaricus was carried out in MRS agar (Oxoid), acidified to 5.4 with acetic acid, followed by aerobic incubation at $37{ }^{\circ} \mathrm{C}$ for $48 \mathrm{~h}$. L. acidophilus and $L$. rhamnosus were grown anaerobically at $37^{\circ} \mathrm{C}$ for $72 \mathrm{~h}$ in MRS agar (Oxoid). B. lactis was counted in MRS agar containing $50 \mathrm{~g} / \mathrm{L}$ cysteine, after jar anaerobic incubation at $37^{\circ} \mathrm{C}$ for $72 \mathrm{~h}$. Anaerobic conditions were ensured by the use of AnaeroGen (Oxoid). Variations with respect to the mean values were presented as standard deviations. Mean values of these parameters were submitted to analysis of variance (ANOVA), using the Statistica Software 6.0
(StatSoft, Tulsa, USA). They were compared using the Tukey test at significance level $\mathrm{p}<0.05$.

Table 1 shows the results obtained for fermentations of low fat milk as such (control) or supplemented with $40 \mathrm{mg} / \mathrm{g}$ of inulin or oligofructose by strains L. bulgaricus St-Lb, L. acidophilus St-La, L. rhamnosus St-Lr or B. lactis St-Bl in binary co-cultures with $S$. thermophilus.

$\mathrm{V}_{\max }$ ranged from $17.0610^{-3} \mathrm{upH} / \mathrm{min}$ (St-Lr in the control) to $23.1710^{-3} \mathrm{upH} / \mathrm{min}$ (St-La in milk supplemented with oligofructose). In the presence of oligofructose and inulin, the average $\mathrm{V}_{\max }$ values obtained with all the co-cultures were $12.2 \%$ and $6.4 \%$ higher than in the control, respectively, and approximately $15 \%$ higher than those obtained in previous study (Oliveira et al., 2009a) both in the presence and in the absence of inulin, probably due to the presence of $0.5 \%$ fat in the milk used in this study. Recent studies reported that fat components present in milk, like conjugated linoleic acid, provided functional characteristics (Oliveira et al., 2009b; Rodrigues et al., 2011). Probably, this component may have positively influenced the fermentation profile and growth of probiotic bacteria.

It should be noted that the time to complete fermentation $\left(\mathrm{T}_{\mathrm{f}}\right)$ ranged from $4.2 \mathrm{~h}$ (St-Lb in the presence of oligofructose) to $11.3 \mathrm{~h}$ (St-Lr in the control), which means that the fermentation profile depended, not only on the interactions between St and the others microorganisms, but also on the type of prebiotic supplemented. In the presence of oligofructose, the average time to complete fermentation by all the binary co-cultures was in fact approximately $21 \%$

Table 1 - Maximum acidification rate $\left(\mathrm{V}_{\max }\right)$, time to reach $\mathrm{pH} 4.5\left(\mathrm{~T}_{\mathrm{f}}\right)$, and viable cell counts in fermentations of low fat milk (M), supplemented with 40 $\mathrm{mg} / \mathrm{g}$ inulin $(\mathrm{M}+\mathrm{I})$ or oligofructose $(\mathrm{M}+\mathrm{O})$, by S. thermophilus in co-culture with L. bulgaricus (St-Lb), L. acidophilus (St-La), L. rhamnosus (St-Lr) or B. lactis (St-Bl)

\begin{tabular}{|c|c|c|c|c|}
\hline Milk & Co-culture & $\mathrm{V}_{\max }\left(10^{-3} \mathrm{pH}\right.$ units $\left./ \min \right)$ & $\mathrm{T}_{\mathrm{f}}(\mathrm{h})$ & Viable cell counts $\left(\log \mathrm{cfu} / \mathrm{mL}^{*}\right)$ \\
\hline M & St-Lb & $20.880 .25^{\mathrm{a}}$ & $4.39 \pm 0.12^{\mathrm{c}}$ & $7.41 \pm 0.21^{\mathrm{c}}$ \\
\hline M & St-La & $19.47 \pm 0.31^{\mathrm{b}}$ & $10.33 \pm 0.21^{\mathrm{k}}$ & $7.35 \pm 0.06^{\mathrm{b}}$ \\
\hline M & St-Lr & $17.06 \pm 0.25^{\mathrm{b}}$ & $11.31 \pm 0.08^{1}$ & $7.03 \pm 0.24^{\mathrm{a}}$ \\
\hline M & St-Bl & $18.91 \pm 0.19^{c}$ & $8.99 \pm 0.18^{\mathrm{i}}$ & $7.67 \pm 0.13^{\mathrm{h}}$ \\
\hline $\mathrm{M}+\mathrm{I}$ & St-Lb & $20.55 \pm 0.25^{\mathrm{h}}$ & $4.26 \pm 0.20^{\mathrm{b}}$ & $7.55 \pm 0.12^{\mathrm{e}}$ \\
\hline $\mathrm{M}+\mathrm{I}$ & St-La & $21.35 \pm 0.24^{\mathrm{j}}$ & $8.55 \pm 0.14^{\mathrm{h}}$ & $7.78 \pm 0.07^{\mathrm{g}}$ \\
\hline $\mathrm{M}+\mathrm{I}$ & St-Lr & $19.52 \pm 0.31^{\mathrm{e}}$ & $9.03 \pm 0.24^{j}$ & $7.88 \pm 0.11^{\mathrm{d}}$ \\
\hline $\mathrm{M}+\mathrm{I}$ & St-Bl & $19.77 \pm 0.18^{\mathrm{f}}$ & $8.41 \pm 0.15^{\mathrm{g}}$ & $8.55 \pm 0.19^{\mathrm{k}}$ \\
\hline $\mathrm{M}+\mathrm{O}$ & St-Lb & $21.22 \pm 0.19^{\mathrm{i}}$ & $4.19 \pm 0.20^{\mathrm{a}}$ & $7.45 \pm 0.12^{\mathrm{f}}$ \\
\hline $\mathrm{M}+\mathrm{O}$ & St-La & $23.17 \pm 0.22^{\mathrm{k}}$ & $7.44 \pm 0.08^{\mathrm{d}}$ & $7.66 \pm 0.07^{\mathrm{i}}$ \\
\hline $\mathrm{M}+\mathrm{O}$ & St-Lr & $20.36 \pm 0.31^{\mathrm{g}}$ & $8.13 \pm 0.11^{\mathrm{e}}$ & $7.44 \pm 0.11^{\mathrm{j}}$ \\
\hline $\mathrm{M}+\mathrm{O}$ & St-B1 & $20.88 \pm 0.22^{\mathrm{a}}$ & $7.99 \pm 0.11^{\mathrm{f}}$ & $8.11 \pm 0.19^{1}$ \\
\hline
\end{tabular}

Means $(n=3) \pm$ standard deviation with different letters in the same column are significantly different $(\mathrm{p}<0.05)$.

*Counts of L. bulgaricus (St-Lb), L. acidophilus (St-La), L. rhamnosus (St-Lr) or B. lactis (St-Bl), according to the microorganism employed along with S. thermophilus. 
and $8 \%$ shorter than in the control and in the presence of inulin, respectively (Table 1). Such an effect demonstrates that both oligofructose and inulin stimulated the metabolism of the binary co-cultures. Moreover, it is noteworthy that the use of these prebiotics decreased, in general, the fermentation time of all the binary co-cultures, mainly of St-Lr, for which the addition of inulin and oligofructose decreased $\mathrm{T}_{\mathrm{f}}$ by no less than $20 \%$ and $28 \%$, respectively, when compared to the control. This last result confirms that the combination of St-Lr and prebiotics could be satisfactorily exploited in the dairy industry (Tannock et al., 2000; Capela et al., 2006; Rodríguez-Alcalá et al., 2011).

Of the two prebiotics, oligofructose accelerated the acidification more than inulin did, likely because its polymerization degree is much lower than that of inulin (Angus et al., 2005), which made its partial hydrolysis quicker.

Table 1 shows the counts after 1 day-storage at $4{ }^{\circ} \mathrm{C}$ since the end of fermentations of co-cultures of $S$. thermophilus with either Lb or the selected probiotics, both in the presence and in the absence of oligofructose or inulin. Viable St counts (results not shown) were not significantly influenced by the type of prebiotic or probiotic used, varying only between 8.9 and $9.1 \log \mathrm{cfu} / \mathrm{mL}$. On the other hand, significant differences were observed for viable counts of the probiotic bacteria, which were strongly influenced by the presence of FOS as well $(p<0.05)$. As expected by the above considerations, the mean probiotics viable counts were $7.8 \%$ and $4.1 \%$ higher than in the control, respectively, in the presence of oligofructose and inulin. The influence of FOS on probiotic survival is consistent with the observations of several authors, who observed a clear beneficial action of these prebiotics on the viability of L. rhamnosus, L. acidophilus, and Bifidobacterium spp. in fermented milk and other dairy products (Dave and Shah, 1996; Oliveira et al., 2009a; Paseephol and Sherkat, 2009).

Finally, St-Bl was the binary co-culture most stimulated by the presence of inulin and oligofructose; it did, in fact, show average viable counts $6 \%$ and $12 \%$ higher, respectively, than in the control. These results demonstrate that the interaction between pre- and probiotics was positive, according to the definition proposed by Gibson and Roberfroid (1995).

According to Angus et al. (2005), both inulin and oligofructose promote the growth of bifidobacteria in absolute terms. Briefly, fructose released from their partial hydrolysis catalyzed by inulinase may be metabolized as an additional carbon and energy source (Mayo et al., 2010). In the presence of external oligosaccharides and polysaccharides like inulin or oligofructose, bifidobacteria are, in fact, able to uptake the monomers from their hydrolysis through the fructose-6-phosphate shunt (McKellar and Modler, 1989; Tharmaraj and Shah, 2003; van der Meulen et al., 2006).

In general, these results as a whole not only confirm $\mathrm{St}-\mathrm{Lb}$ as the best co-culture for yoghurt preparation, but also suggest that the alternative probiotics employed in this study (La, Lr, and $\mathrm{Bl}$ ) would be able to ensure satisfactory results in terms of fermentation profile. Moreover, oligofructose and to some extent also inulin were shown to significantly accelerate either acidification or fermentation, thus proving to be interesting prebiotics to improve the production of functional dairy products.

\section{Acknowledgments}

The authors acknowledge the financial support of Fundação de Amparo à Pesquisa do Estado de São Paulo (FAPESP) and Coordenação de Aperfeiçoamento de Pessoal de Nível Superior (CAPES), Brazil, for the PhD fellowships of R.P.S. Oliveira.

\section{References}

Angus F, Smart S, Shortt C (2005) Prebiotic ingredients with emphasis on galacto-oligosaccharides and fructo-oligosaccharides. In: Tamime AY (ed) Probiotic Dairy Products. Blackwell Publishing, Marcel Dekker, Oxford, pp 120-137.

Capela P, Hay TKC, Shah NP (2006) Effect of cryoprotectants, prebiotics and microencapsulation on survival of probiotic organisms in yoghurt and freeze-dried yoghurt. Food Res Int 39:203-211.

Dave RI, Shah NP (1996) Evaluation of media for selective enumeration of Streptococcus thermophillus, Lactobacillus delbrueckii subsp. bulgaricus, Lactobacillus acidophilus and bifidobacteria. J Dairy Sci 79:1529-1536.

Gibson GR, Roberfroid MB (1995) Dietary modulation of the human colonic microbiota: Introducing the concept of prebiotics. J Nutr 125:1401-1412.

Mayo B, Aleksandrzak-Piekarczyk T, Fernández M, Kowalczyk M, Álvarez-Martín P, Bardowski J (2010) Updates in the metabolism of lactic acid bacteria. In: Mozzi et al. (eds) Biotechnology of Lactic Acid Bacteria: Novel Applications. Wiley-Blackwell, Iowa, pp 3-33.

McKellar RC, Modler HW (1989) Metabolism of fructo-oligosaccharides by Bifidobacterium spp. Appl Microbiol Biotechnol 31:537-541.

Niness KR (1999) Inulin and oligofructose: What are they? J Nutr 129:1402-1406.

Oliveira RPS, Perego P, Converti A, Oliveira MN (2009a) Growth and acidification performance of probiotics in pure culture and co-culture with Streptococcus thermophilus: The effect of inulin. LWT - Food Sci Technol 42:10151021.

Oliveira RPS, Florence ACR, Silva RC, Perego P, Converti A, Gioielli LA, Oliveira MN (2009b) Effect of different prebiotics on the fermentation kinetics, probiotic survival and fatty acid profiles in nonfat symbiotic fermented milk. Int $\mathbf{J}$ Food Microbiol 128:467-472.

Oliveira RPS, Perego P, Oliveira MN, Converti A (2011) Effect of inulin as prebiotic and synbiotic interactions between probiotics to improve fermented milk firmness. J Food Eng 107:36-40.

Paseephol T, Sherkat F (2009) Probiotic stability of yoghurts containing Jerusalem artichoke inulins during refrigerated storage. J Funct Foods 1:311-318. 
Rodrigues D, Rocha-Santos TAP, Pereira CI, Gomes AM, Malcata FX, Freitas AC (2011) The potential effect of FOS and inulin upon probiotic bacterium performance in curdled milk matrices. Food Sci Technol 44:100-108.

Rodríguez-Alcalá LM, Braga T, Malcata FX, Gomes A, Fontecha J (2011) Quantitative and qualitative determination of CLA produced by Bifidobacterium and lactic acid bacteria by combining spectrophotometric and Ag+-HPLC techniques. Food Chem 125:1373-1378.

Tannock GW, Munro K, Harmsen HJM, Welling GW, Smart J, Gopal PK (2000) Analysis of the faecal microflora of human subjects consuming a probiotic product containing Lactobacillus rhamnosus DR 20. Appl Environ Microbiol $66: 2578-2588$.
Tharmaraj N, Shah NP (2003) Selective enumeration of Lactobacillus delbrueckii ssp. bulgaricus, Streptococcus thermophilus, Lactobacillus acidophilus, bifidobacteria, Lactobacillus casei, Lactobacillus rhamnosus and Propionibacteria. J Dairy Sci 86:2288-2296.

van der Meulen R, Verbrugghe TAK, de Vuyst L (2006) Kinetic analysis of bifidobacterial metabolism reveals a minor role for succinic acid in the regeneration of $\mathrm{NAD}^{+}$through its growth-associated production. Appl. Environ. Microbiol 72:5204-5210.

Vasiljevic T, Shah NP (2008) Probiotics - From Metchnikoff to bioactives. Int Dairy J 18:714-728.

All the content of the journal, except where otherwise noted, is licensed under a Creative Commons License CC BY-NC. 